\title{
Padrões morfossintáticos da inferência e da dedução em língua portuguesa
}

DOI: http://dx.doi.org/10.21165/el.v49i1.2694

\section{Vítor Henrique Santos da Silva'}

\section{Resumo}

A evidencialidade é utilizada para indicar a fonte da informação contida em um enunciado ou o meio pelo qual essa informação foi obtida. A Gramática Discursivo-Funcional, teoria que embasou este estudo, reconhece diferentes subtipos desse fenômeno, dois dos quais interessaram a este trabalho: a inferência, que é um raciocínio assentado no conhecimento interno do falante; e a dedução, que é um cálculo mental baseado em evidências perceptuais. O objetivo deste estudo foi verificar se há marcas morfossintáticas distintas para a codificação dos dois subtipos em língua portuguesa. Os dados indicam que a inferência apresenta mais possibilidades de expressão do que a dedução, já que esta é codificada apenas em relações de complementação e justaposição, e aquela, além dessas duas, é também expressa por modificação e parentetização.

Palavras-chave: evidencialidade; inferência; dedução; Gramática Discursivo-Funcional.

1 Universidade Estadual Paulista "Júlio de Mesquita Filho" (UNESP), São José do Rio Preto, São Paulo, Brasil; vitorhss20@gmail.com; https://orcid.org/0000-0003-4649-2170. 


\section{Les modèles morphosyntaxiques de l'inférence et de la déduction en langue portugaise}

\section{Résumé}

Le médiatif est utilisé pour indiquer la source de l'information contenue dans un énoncé ou le moyen par lequel cette information a été obtenue. La Grammaire FonctionnelleDiscursive, qui est le cadre théorique de cette étude, reconnaît de différents types de ce phénomène, dont deux entre eux ont intéressé à ce travail: l'inférence, qui est un raisonnement basé sur la connaissance interne au locuteur ; et la déduction, qui est un calcul mental fondé sur des preuves perceptives. Le but de cette étude était de vérifier s'il y a des marques morphosyntaxiques distinctes pour la codification des deux soustypes en portugais. Les données indiquent que l'inférence présente plus de possibilités d'expression que la déduction, puisque celle-ci n'est codifiée que par complémentation et juxtaposition, et celle-là, en plus de ces deux, est également exprimée par modification et parenthésage.

Mots-clés: médiatif; inférence; déduction; Grammaire Fonctionelle-Discoursive.

\section{Introdução}

A evidencialidade é uma categoria qualificacional utilizada para indicar a fonte da informação veiculada em um enunciado ou o meio pelo qual essa informação foi obtida. A Gramática Discursivo-Funcional (HENGEVELD; MACKENZIE, 2008), doravante GDF, aparato teórico utilizado nesta pesquisa, define essa categoria com base no escopo do elemento evidencial, reconhecendo atualmente cinco subtipos (HENGEVELD; FISCHER, 2018). A esta pesquisa interessaram dois deles, que marcam uma informação como proveniente de um cálculo mental, diferindo com relação à evidência utilizada para o raciocínio: a inferência está assentada no conhecimento de mundo do falante, ao passo que a dedução é baseada em evidências perceptuais.

Tendo em vista a relevância dessa distinção para a gramática de várias línguas, como a do Tariana (AIKHENVALD, 2003), por exemplo, que apresenta elementos gramaticais distintos para codificar uma inferência e uma dedução, a pesquisa aqui descrita tem o objetivo de verificar se o português brasileiro marca, por meios morfossintáticos, a diferença semântica existente entre esses subtipos. Os resultados apresentados neste trabalho são parte de um projeto maior, realizado como dissertação de mestrado e apresentado em Silva (2020), que busca não só verificar a distinção morfossintática entre inferência e dedução, mas também investiga como os dois subtipos interagem com outras categorias qualificacionais, tais como, tempo e modo. 
Na seção 2, há a apresentação do aparato teórico utilizado para a pesquisa e do fenômeno estudado sob a luz dessa teoria; na seção 3, são apresentados o córpus e os critérios de seleção e de análise das ocorrências; na seção 4, encontra-se a análise dos dados; e, por fim, na seção 5, são feitas as considerações finais.

\section{Fundamentação teórica}

\subsection{A Gramática Discursivo-Funcional}

Este trabalho foi embasado pela Gramática Discursivo-Funcional (HENGEVELD; MACKENZIE, 2008), uma teoria que entende o discurso como estratificado em níveis e camadas hierárquicos, em que as operações dos níveis superiores determinam as operações dos níveis inferiores. A GDF é entendida como o Componente Gramatical de um modelo maior de interação verbal, composto também pelos Componentes Conceitual, Contextual e de Saída. O Componente Conceitual lida com as intenções e com as ideias do falante, sendo o motivador da produção linguística realizada no Componente Gramatical. O Componente Contextual, por sua vez, é responsável por armazenar informações do discurso corrente e de discursos anteriores, assim como outras informações contextuais importantes para a interação. O Componente Gramatical é responsável pelas operações linguísticas de formulação e decodificação, traduzindo as intenções comunicativas do falante e dando forma virtual a elas. Por último, o Componente de Saída trata da expressão, por meio da fala, da escrita ou da gestualidade, do que foi produzido no Componente Gramatical.

A GDF está organizada em quatro níveis hierárquicos que, por sua vez, estão subdivididos em camadas hierárquicas e não hierárquicas. O Nível Interpessoal (da pragmática) é responsável por captar aspectos que interferem na relação entre falante e ouvinte e por determinar as relações discursivas que precisam estabelecer-se para que as intenções comunicativas possam ser transmitidas de forma eficiente.

O Nível Representacional (da semântica) é responsável pela representação do mundo extralinguístico. Sua camada mais alta é o Conteúdo Proposicional, que diz respeito a um construto mental que não pode ser localizado no tempo nem no espaço e que é avaliado apenas pelo seu estatuto de verdade ou pela fonte da informação. Na sequência, encontra-se a camada do Episódio, que consiste em um ou mais Estados de Coisas que demonstram unidade ou continuidade de Tempo, Lugar, Participantes e Domínios de Realidade (HENGEVELD; FISCHER; GRANDIS, 2018). A terceira camada mais alta na hierarquia é o Estado de Coisas, um evento que pode ser localizado no tempo e no espaço e pode ser avaliado em termos de realização. Em seguida, está a Propriedade Configuracional, que é o conjunto de moldes de predicação disponíveis em uma língua, consistindo em uma relação entre outras camadas não hierárquicas entre si. Elas podem ser: Propriedade Lexical, que especifica outras entidades e não tem existência 
independente, avaliada por sua aplicabilidade; Indivíduo, que é uma entidade concreta e tangível, que ocupa uma porção de espaço; Tempo, que diz respeito às categorias temporais existentes em uma língua; Lugar, que é uma porção de espaço em que se situam outras entidades semânticas; e outras categorias minoritárias, entre elas, a Maneira, a Razão e a Quantidade, que não são utilizadas na definição dos subtipos evidenciais e que, por isso, não serão apresentadas em detalhes.

O Nível Morfossintático recebe o input das operações de formulação que ocorrem no Nível Interpessoal e no Nível Representacional e organiza essa informação, por meio da operação de codificação morfossintática, na ordem em que os elementos deverão ser expressos pelo componente de saída. A camada mais alta na hierarquia do Nível Morfossintático é a Expressão Linguística, que consiste em um conjunto de pelo menos uma Oração, um Sintagma ou uma Palavra que podem ser utilizados de forma independente. Na sequência, há a camada da Oração, que pode ser composta por combinações de Sintagmas, Palavras e Orações encaixadas. A camada seguinte na hierarquia é o Sintagma, que pode ser composto por combinações de Palavras, outros Sintagmas e até mesmo Orações encaixadas. Por último, há a camada da Palavra, que consiste na combinação de Morfemas, outras Palavras e até mesmo Sintagmas e Orações.

O Nível Fonológico, por sua vez, é o responsável por organizar toda a informação proveniente dos níveis anteriores e convertê-la em uma representação digital que servirá de input ao Componente de Saída, o qual expressará o conteúdo linguístico produzido no Componente Gramatical. Tendo em vista que a análise apresentada à frente não considera fatores fonológicos, esse nível não será discutido detalhadamente.

\subsection{Subtipos evidenciais segundo a GDF}

A GDF trata a evidencialidade como uma categoria ampla que abarca fenômenos de natureza pragmática e semântica, como dito acima. Nesse aparato teórico, fenômenos como a evidencialidade são definidos com base em seu escopo, o que permite prever, inclusive sua interação com outras categorias qualificacionais, como tempo, modo, aspecto etc. A seguir, são apresentados os subtipos evidenciais reconhecidos atualmente pela GDF.

Segundo Hengeveld e Fischer (2018), a citação marca um enunciado como originalmente produzido por outro falante, exatamente da maneira como é apresentado. Por ter escopo inclusive sobre a llocução, esse subtipo evidencial atua na camada do Ato Discursivo. A seguir, um exemplo de como funciona essa categoria em português: 
(1) "Vocês roubaram meus sonhos e infância", diz Greta Thunberg na ONU. (internet²)

Nesse exemplo, o enunciado Vocês roubaram meus sonhos e infância é atribuído a outro indivíduo por meio do verbo dizer e das aspas. Essas últimas indicam também que ele é reproduzido do modo como foi originalmente proferido, e essa característica confere a esse evidencial o estatuto de citação.

O segundo subtipo evidencial do Nível Interpessoal é a reportatividade, que também marca uma informação como originalmente produzida por outrem, recontada com as próprias palavras do falante. Esse subtipo evidencial está alocado na camada do Conteúdo Comunicado, pois ele está sob o escopo da Ilocução, como demonstram Hengeveld e Fischer (2018). A seguir, um exemplo de reportatividade em língua portuguesa:

(2) Eu ouvi que você estava trabalhando em um projeto solo. (VENDRAME, 2010, p. 115).

Nessa ocorrência, o falante indica, por meio do verbo ouvir, que o Conteúdo Comunicado que você estava trabalhando em um projeto solo foi originalmente produzido por outra pessoa. Nesse caso, a informação é recontada com as próprias palavras do falante, configurando reportatividade.

No Nível Representacional, encontram-se três subtipos evidenciais. O de maior escopo é a inferência, o qual recai sobre a camada do Conteúdo Proposicional, que diz respeito a um cálculo mental assentado no conhecimento de mundo do falante. Segundo Hengeveld e Hattnher (2015), a inferência atua sobre essa camada porque a evidência utilizada como base para o cálculo mental é de natureza proposicional, como se observa a seguir:

(3) Não podemos nos agarrar a nada. Conheceste o Hélio ao nascer e acompanhaste o seu crescimento. Embora não tenhas tido um filho, sei, sempre soube pelo teu olhar, que compreendes o sentido mais profundo da paternidade. (KAPP-BARBOSA, 2017, p. 121).

Nesse exemplo, o falante infere que seu interlocutor compreende o sentido mais profundo da paternidade tendo como base o que sabe sobre paternidade e sobre os hábitos de seu interlocutor. Como a base para o cálculo mental é um conhecimento, a marca evidencial se caracteriza como uma inferência.

O segundo subtipo mais alto na hierarquia do Nível Representacional é a dedução, que é um cálculo mental assentado em evidências perceptuais. Ela tem escopo sobre a camada do Episódio porque é concebida como uma relação entre eventos, sendo eles a

2 Disponível em: https://veja.abril.com.br/mundo/voces-roubaram-meus-sonhos-e-infancia-dizgreta-thunberg-na-onu/. 
percepção que embasa o cálculo mental e o evento deduzido. Um exemplo de dedução pode ser visto a seguir:

(4) Sei, pelo barulho do encanamento do edifício, que o vizinho do andar de cima já acordou e está escovando os dentes. (KAPP-BARBOSA, 2017, p. 125).

Na ocorrência (4), a evidência utilizada para o falante deduzir que o vizinho do andar de cima já acordou e está escovando os dentes é uma percepção sonora, o barulho do encanamento do edifício, configurando, portanto, uma dedução.

O último subtipo evidencial é a percepção de evento, que diz respeito à percepção de um Estado de Coisas por meio de um dos cinco sentidos. Por esse motivo, esse subtipo evidencial tem escopo sobre a camada do Estado de Coisas. A ocorrência a seguir ilustra esse fenômeno:

(5) Quanto às tremidinhas também já senti várias vezes. Mas, gente, fiquei tão feliz agora. Senti ela mexer de verdade! Agorinha mesmo. Nada brusco, uma cosquinha, mas que deu para ter certeza que é ela. (VENDRAME, 2010, p. 135).

Nessa ocorrência, a falante está grávida e sente seu filho mexer dentro de sua barriga. Como o Estado de Coisas é percebido diretamente por meio do tato, o verbo evidencial assume o sentido de percepção direta.

\section{Universo de pesquisa}

\subsection{0 córpus}

Para a análise apresentada neste trabalho, foram selecionados seis verbos que têm, entre outras funções, a capacidade de codificar a inferência e a dedução, sendo eles inferir, deduzir, concluir, perceber, observar e ver. A escolha desses verbos foi motivada pela classe semântica atribuída a eles: enquanto inferir, deduzir e concluir são considerados verbos cognitivos, perceber, observar e ver são entendidos como verbos de percepção. A pesquisa da qual deriva este trabalho tem o intuito de verificar se, por ser embasada por uma percepção sensorial, a dedução seria preferencialmente expressa por verbos de percepção e se, por não necessitar de uma evidência externa, a inferência seria neutra quanto ao elemento que a expressa. Não é objetivo do recorte aqui realizado desenvolver essa discussão, que, entretanto, poderá ser conferida em Silva (2020).

As ocorrências analisadas são retiradas de dois córpus, a saber: o Corpus Brasileiro (SARDINHA; MOREIRA FILHO; ALAMBERT, 2010), que, segundo seu site oficial, é um projeto do Grupo de Estudos de Linguística de Corpus (GELC), do Programa de Pós- 
Graduação em Linguística Aplicada da PUC-SP, financiado pela FAPESP, e que conta com aproximadamente um bilhão de palavras do português brasileiro contemporâneo; e o Timestamped JSI (TRAMPUS; NOVAK, 2012), que é um projeto do Instituto Jozef Stefan, da Eslovênia, composto por textos da internet, de vários países lusófonos, que conta com mais de 2,7 bilhões de palavras. A busca das ocorrências foi realizada com o auxílio da ferramenta Sketch Engine, uma plataforma on-line que permite trabalhar com cerca de 500 córpus, divididos entre mais de 90 línguas, e que dá acesso aos dois córpus utilizados nesta pesquisa.

No levantamento dos dados, foram escolhidas apenas ocorrências em que a evidência utilizada como base para o cálculo mental estivesse disponível no contexto provido pelo Sketch Engine, já que, a princípio, essa seria a única maneira de diferenciar a inferência da dedução. Além disso, foram selecionadas apenas ocorrências em que o verbo analisado: i) possui sentido de cálculo mental; ii) está no presente do indicativo; iii) na primeira pessoa do singular; e iv) fora do escopo da negação. A escolha do primeiro critério deve-se ao fato de que os verbos selecionados são polissêmicos, e os sentidos que interessam a este trabalho são apenas aqueles relacionados à codificação de um cálculo mental. O segundo critério foi selecionado a fim de evitar ambiguidades entre um uso evidencial propriamente dito e o simples relato de uma ação mental, que pode acontecer com o verbo no passado. Além disso, como o falante tem de ter feito a inferência ou a dedução antes do momento de enunciação ou concomitantemente a ele, o futuro é bloqueado em um verbo evidencial. O terceiro critério justifica-se pela natureza dêitica da evidencialidade (HAAN, 2005; HASSLER, 2010), já que ela apresenta uma relação entre o falante e seu enunciado, e a pessoa gramatical utilizada para marcar o falante é, canonicamente, a primeira pessoa do singular. O último critério é motivado pelo bloqueio do sentido evidencial quando a negação atua sobre um dos verbos escolhidos, já que ela nega a própria obtenção da informação por aquele meio, como em ?0 chão está seco, não deduzo que choveu. Por outro lado, a negação pode atuar sobre o elemento inferido ou deduzido, como em o chão está seco, deduzo que não choveu.

Inicialmente, foi proposto que se trabalhasse com 50 ocorrências de cada verbo, o que não foi possível no caso de inferir e deduzir, que apresentam baixa frequência de uso e poucas ocorrências utilizáveis (depois de realizada a seleção com os critérios apresentados anteriormente). O número de ocorrências da análise pode se encontrado na tabela a seguir: 
Tabela 1. Número de ocorrências evidenciais

\begin{tabular}{c|c}
\hline Verbo evidencial & Número de ocorrências \\
\hline Inferir & 37 \\
\hline Deduzir & 40 \\
\hline Concluir & 50 \\
\hline Perceber & 50 \\
\hline Observar & 50 \\
\hline Ver & 50 \\
\hline Total & 277 \\
\hline
\end{tabular}

Fonte: Elaboração própria

Na análise que segue, duas das ocorrências levantadas não serão consideradas, pois há uma sobreposição entre inferência e dedução no cálculo mental contido nelas, como se vê a seguir:

(6) Eu olhei e tinha quatro rapazes armados, com arma longa. Eu deduzo que seja fuzil. (JSI:globo)

Nessa ocorrência, o cálculo mental é fortemente amparado por uma percepção sensorial, já que é a visão que indica o tamanho e o formato da arma que está sendo segurada. Além disso, ele também é fortemente amparado pelo conhecimento do falante sobre armamentos, já que a identificação do tipo de arma só é possível porque o falante tem conhecimento do que é ou não um fuzil. Desse modo, por não poder ser definido a priori como inferência ou dedução, essa e outra ocorrência análoga foram excluídas da análise aqui apresentada.

\subsection{Critérios de análise das ocorrências}

A fim de verificar a existência ou não de distinção formal entre inferência e dedução, os seguintes critérios de análise foram propostos: i) subtipo evidencial, para identificar as ocorrências como inferência ou dedução; ii) relação morfossintática entre o evidencial e o elemento inferido ou deduzido (EID), que pode ser de complementação, justaposição, modificação ou parentetização; e iii) forma da estrutura inferida ou deduzida, que pode ser uma Oração finita, não finita ou um Sintagma não oracional. 


\section{Análise dos dados}

A Oração evidencial e o EID podem estabelecer diferentes tipos de relações morfossintáticas, como se observa na tabela a seguir:

Tabela 2. Padrões morfossintáticos dos evidenciais

\begin{tabular}{l|c|c}
\hline \multirow{2}{*}{ Relação morfossintática } & \multicolumn{2}{|c}{ Subtipo evidencial } \\
\cline { 2 - 3 } & Inferência & Dedução \\
\hline \multirow{2}{*}{ Complementação } & $90 \%$ & $92 \%$ \\
$(224)$ & $(24)$ \\
\hline \multirow{2}{*}{ Justaposição } & $2 \%$ & $8 \%$ \\
& $(5)$ & $(2)$ \\
\hline \multirow{2}{*}{ Modificação } & $3,2 \%$ & - \\
\hline \multirow{2}{*}{ Parentetização } & $(8)$ & $(0)$ \\
\hline \multirow{2}{*}{ Total } & $4,8 \%$ & - \\
& $(12)$ & $(0)$ \\
\hline
\end{tabular}

Fonte: Elaboração própria

Como se vê na tabela 2, a relação de complementação é a mais frequente para codificar os subtipos evidenciais analisados neste trabalho, representando $90 \%$ das ocorrências de inferência e 92\% das ocorrências de dedução. Além disso, ambas podem ser codificadas pela relação de justaposição, que diz respeito a $2 \%$ das inferências analisadas e $8 \%$ das deduções. No córpus, a modificação e a parentetização são encontradas apenas com a inferência, representando 3,2\% e 4,8\%, respectivamente, das ocorrências desse subtipo.

A relação de complementação é aquela que apresenta mais variedade de combinações entre o evidencial e o EID, já que esse último pode ser de diferentes tipos. Nas Orações complexas, o verbo evidencial é núcleo da Oração matriz, e o EID se dá sobre a forma de uma Oração completiva, que ocupa a posição de Objeto do verbo evidencial. Essa configuração, em que a completiva é uma Oração finita, é utilizada para veicular tanto a inferência (7) quanto a dedução (8), como se vê a seguir: 
(7) Amava a família e perdeu filhos quando eram ainda crianças. Morreu de causas desconhecidas, mas deduzo que foi de tuberculose. Havia uma endemia de tísica na época em Londres e muitos padeceram. (CB:Jour:News).

(8) Percebo que o senhor é um entusiasta da sua linha de pensamento, como sou da minha disse ele. - Observo pelo seu indicador que o senhor faz os seus próprios cigarros. (JSI:uol).

Em (7), a partir do conhecimento de que havia uma endemia de tuberculose na época em que a pessoa citada morreu, o falante infere que a causa da morte foi essa doença. Como a base para o raciocínio é um conhecimento, essa ocorrência se caracteriza como uma inferência. Já em (8), o falante percebe, por meio da visão, vestígios de produção de cigarro nos dedos de seu interlocutor e deduz então que ele faz os seus próprios cigarros. A evidência em que se assenta o cálculo mental é uma percepção por meio dos sentidos, o que configura uma dedução.

Outro tipo de estrutura que pode aparecer como argumento do predicado evidencial são as Orações não finitas. Elas estão restritas às ocorrências de inferência e a tipos específicos de predicação, sendo eles: predicação de um lugar adjetival (10), predicação de classificação (11), predicação de identificação (12) e predicação de existência (13).

(10) Segundo Soares (1999), que também pesquisou livros didáticos de $1^{\mathrm{a}}$ a $4^{\mathrm{a}}$ série do Ensino Fundamental, são vários os problemas advindos dessa maneira inadequada de escolarizar a literatura e cita, entre eles, a desestruturação dos textos, a seleção limitada de autores e obras e a fragmentação do texto, o qual infiro ser o mais grave, pois isso implicará na formação do conceito de texto por parte do aluno e, muitas vezes também, por parte do professor. (CB:Aca:TaD).

Nessa ocorrência, a partir do que sabe sobre as implicações advindas do ensino com textos fragmentados, o falante infere que esse é o problema mais grave das maneiras inadequadas de se ensinar literatura. A propriedade grave está predicando sobre o pronome o qual, que, por sua vez, faz referência ao Sintagma Nominal a fragmentação do texto. O evidencial inferencial marca que essa caracterização é fruto de um cálculo mental.

(11) Não é pois pelo aviltamento dos povos dominados que se devem julgar das disposições naturais do homem a favor ou contra a servidão, mas sim pelo prodígio realizado por todos os povos livres para se defenderem da opressão. Sei que os primeiros nada fazem senão enaltecer continuamente a paz e o sossego de que gozam sob seus grilhões e que chamam de paz à mais miserável das servidões, mas quando vejo os outros sacrificarem os prazeres e o repouso, a riqueza, o poder e a própria vida pela conservação deste único bem tão desprezado por aqueles que o perderam [...] concluo não poderem ser os escravos os mais indicados para raciocinar sobre a liberdade. (CB:Aca:Art). 
No exemplo (11), com base no comportamento que observa em povos livres e povos escravizados, o falante conclui que os últimos não são os mais adequados para raciocinar sobre a liberdade. A classificação negativa se dá entre os escravos e os mais indicados para raciocinar sobre a liberdade, que é então marcada como decorrente de um raciocínio cuja base é um conhecimento.

(12) Conversamos sobre o "homem da net", que eu mais tarde deduzo ser alguém da operadora de telefonia, porque "A Helena quer a net aí pra falar com a família dela lá no Ceará, diz ela que dá pra ver tudo o que acontece lá direto do celular, então ele veio aí instalar, mas não dava de jeito nenhum e depois deu". (JSI:tribunademinas).

Nessa ocorrência, o falante identifica o homem da net como alguém da operadora de telefonia, tendo como base o relato da mulher com quem fala. Essa identificação é então marcada por um evidencial inferencial, para demonstrar que a informação provém de um cálculo mental.

(13) O relator dos embargos, ministro Ricardo Lewandowski, deu provimento ao pedido e entendeu não estar configurada prática de crime. "Concluo não haver prova de que a acusada tenha de qualquer forma interferido na escolha de livros a serem adquiridos para o programa de educação de jovens e adultos". (JSI:conexaoto).

Nesse exemplo, a partir da análise dos fatos, o falante infere que não existem provas que demonstrem a culpabilidade da acusada. Como o raciocínio está assentado na análise de documentos e outros tipos de informações verbais, o uso do verbo concluir configura uma inferência.

O que todas essas ocorrências têm em comum é que o núcleo das Orações não finitas são verbos de apoio, ou seja, que não têm conteúdo semântico e são introduzidos apenas no Nível Morfossintático da gramática. Essa parece ser a motivação para que assumam a forma de Oração não finita quando estão sob o escopo do evidencial inferencial.

Além disso, a razão para o complemento da dedução não ser encontrado sob a forma de uma Oração não finita parece ser a proximidade temporal e espacial que essa forma implica. Desse modo, em uma expressão como vejo que as crianças estão brincando (porque ouço barulho de bola), se a completiva aparecesse sob a forma não finita, vejo as crianças brincarem, o sentido evidencial necessariamente mudaria e passaria a ser de uma percepção de evento, pois implicaria que o falante presencia o evento as crianças brincarem.

Os verbos evidenciais também podem aparecer sob a forma de Orações simples, casos em que a posição de Objeto é ocupada por um pronome que faz referência à proposição que contém o EID, como se vê nos exemplos a seguir: 
(14) Nós já nos esbarramos por aí. Porque, provavelmente, moramos no mesmo bairro e pegamos o mesmo ônibus. Deduzo isso de forma simples já que foi neste veículo que eu perdi o meu Kindle. (JSI:papodehomem).

(15) Eu também percebo se estão com problema ou nervosos. Eu acho que a minha demonstração é na voz. Eu percebo isso na voz das pessoas, na forma de se expressar. Entre as colegas você sente pela voz quando elas estão tristes, muda totalmente. [...]. Então, eu vejo diferença: a voz alegre é mais clara, mais ativa; e a voz triste é para dentro, falta entusiasmo, é pausada. (CB:Aca:Art).

Em (14), o trecho Porque, provavelmente, moramos no mesmo bairro e pegamos o mesmo ônibus não recebe nenhuma marca evidencial. Entretanto, o falante retoma essa informação, por meio do pronome isso, e a caracteriza como inferida, apresentando inclusive a evidência que sustenta sua afırmação. Em (15), o falante deduz o estado emocional de alguém a partir das características sonoras da voz da pessoa. É importante salientar que a base para o cálculo mental não é o conteúdo das palavras, mas sim o modo como o som é articulado, e, por isso, configura uma dedução.

Outro tipo de Oração evidencial simples é encontrado quando o Objeto do verbo inferencial é um nome proposicional, como se vê no seguinte exemplo:

(16) Portanto, o mesmo livro de capa vermelha deve dar a origem a duas cores diferentes. Entretanto, infiro a consciência-mediata-de-outros através de seus relatos verbais e seus relatos verbais "vermelho" são semelhantes aos meus. (CB:Aca:Art).

Nessa ocorrência, por meio do relato das outras pessoas, o falante infere a consciênciamediata delas. Já que a base para o cálculo mental são informações transmitidas por outrem, esse caso configura uma inferência. Nesse tipo de ocorrência, o Conteúdo Proposicional que serve de argumento Inativo ${ }^{3}$ ao predicado evidencial não contém todas as camadas hierarquicamente inferiores do Nível Representacional, como acontece com os Conteúdos Proposicionais codificados por Orações; por ser um Sintagma Nominal, o Conteúdo Proposicional consiste em uma (relação de) Propriedade(s) apenas.

Além da complementação, os verbos evidenciais ainda podem estabelecer uma relação de justaposição com o EID, como se observa nos seguintes exemplos:

(17) [...] o que meu pai falava era respeitado, na minha casa eu aprendi a honrar pai e mãe só assim eu poderia ser feliz e ter paz, hoje percebo porque tenho filho e uma esposa linda e vivo em paz. (JSI:politacareal).

3 Em uma predicação de dois lugares, como eu infiro a consciência-mediata-de-outros, o argumento Inativo é o elemento que desempenha um papel mais passivo, nesse caso, a consciência-mediatade-outros, enquanto o argumento Ativo é o que tem papel mais ativo, nesse caso, eu. 
(18) E o homem insiste. Abre os braços um pouco languidamente. Meneia a cabeça. Argumenta algo em seu favor - deduzo pela maneira como ele leva as mãos em concha, as pontas dos dedos contra o próprio peito. (JSl:tribunademinas).

Em (17), o falante infere que uma pessoa só é feliz e tem paz se honrar os pais, tendo como base para o cálculo mental sua própria experiência, já que sempre respeitou essa premissa e, atualmente, vive em paz. Por ter como base as experiências do falante adquiridas ao longo de sua vida, essa ocorrência caracteriza uma inferência. Já em (18), a evidência utilizada pelo falante é uma percepção visual, já que ele infere que o homem argumenta algo a seu favor a partir dos gestos que observa o homem fazer. Desse modo, essa ocorrência é marcada por uma dedução.

Nos dois casos, as Orações evidenciais não apresentam dependência semântica nem morfossintática da Oração que contém o EID, podendo ocorrer por si mesmas. A relação entre as duas partes do enunciado pode ser recuperada no Componente Contextual, e essa recuperação é auxiliada pelas Orações que contêm a evidência utilizada no cálculo mental.

A dedução, nos dados analisados, está restrita à complementação e à justaposição. A inferência, por outro lado, pode ser encontrada em outras relações morfossintáticas, como a modificação, que ocorre quando o verbo evidencial está contido em uma Oração modificadora, a qual pode ter escopo sobre outra Oração, como em (19), ou sobre Sintagmas não oracionais, como em (20) e (21):

(19) Não é feliz com meu pai, pelo que observo, leva a mesma vida que minha defunta mãe! (CB:Aca:TaD).

Nessa ocorrência, o falante infere que sua madrasta não é feliz com seu pai comparando a vida que ela leva com a que sua mãe levava. Como o cálculo mental está assentado em um conhecimento interno ao falante, esse uso do verbo observar configura uma inferência. O escopo da inferência recai sobre toda a Oração Não é feliz com meu pai, ao passo que leva a mesma vida que minha defunta mãe! apresenta a evidência que o falante utiliza para fazer sua afırmação. Não é possível entender que essa última Oração está sobre o escopo do evidencial porque ela apresenta llocução diferente da contida na Oração inferencial. Como esse subtipo atua em uma camada hierarquicamente inferior à da llocução, não pode ter escopo sobre ela.

(20) José Ermírio, seu filho mais velho, figura humana singular pelo que deduzo de relatos a seu respeito, foi o primeiro diretor da FIESP. (CB:Pol:SoC).

Nesse exemplo, a partir de relatos sobre uma pessoa, o falante infere que esse indivíduo foi uma figura humana singular. A atribuição da inferência não é feita à Oração principal 
José Ermírio foi o primeiro diretor da FIESP, mas ao aposto de um de seus constituintes, que marca figura humana singular, um Sintagma Nominal, como sendo fruto de um cálculo mental.

(21) Estamos diante de um projeto em torno do qual, pela primeira vez nesta Casa, se vislumbra um grau de consenso inacreditável. No entanto, não se quer votar o projeto, pois foi rompido um acordo com o PT, relacionado a outro projeto - ou o acordo não era bem assim, ou tem que ser discutido depois. Não podemos prejudicar os trabalhadores em função de um desacordo, pelo que percebo, dentro da própria bancada do PT. (CB:Pol:SoC).

Na ocorrência (21), com base na atitude dos outros parlamentares, o falante infere que há um desacordo dentro da bancada de um dos partidos. Nela, a Oração evidencial modificadora tem escopo sobre um Sintagma Preposicional, que serve como argumento para o nome desacordo.

Como é possível observar nos exemplos apresentados anteriormente, a modificação tem maior mobilidade no enunciado do que a complementação e a justaposição, já que a Oração modificadora pode ter escopo tanto sobre Orações quanto sobre unidades menores que a Oração, e seu posicionamento varia a fim de demonstrar esse escopo. Essa relação morfossintática se mostra, assim, um recurso do qual o falante dispõe para marcar também como inferidas unidades semânticas codificadas, no Nível Morfossintático, pelas camadas do Sintagma e da Palavra, o que não é visto nas outras duas relações apresentadas anteriormente.

Uma última relação morfossintática é encontrada especificamente com os evidenciais inferenciais, sendo ela a parentetização. Essa relação pode ser considerada um tipo de cossubordinação, já que não apresenta dependência morfossintática da Oração com a qual se relaciona, mas demonstra dependência pragmática dessa outra. A Oração evidencial parentética funciona como um comentário do falante, marcando um elemento como inferido, e se localiza nas adjacências de outra Oração, como em (22) e (23), quando o falante pretende marcar toda ela como inferida, ou é inserida no meio de outra Oração, como em (24), quando o falante deseja marcar apenas um constituinte como inferido.

(22) Porém, permita que eu me concentre - como há de ser a sua intenção, concluo - na crise econômica. (JSl:uol).

O contexto mais amplo de (22) é que esse enunciado está inserido em um texto que trata da crise econômica, e, nos trechos imediatamente anteriores a esse, o autor discorre sobre a origem da palavra crise, na medicina. Por se tratar de um texto sobre outro assunto, o autor pode afirmar que o real objeto de interesse do leitor é a crise econômica, e não a origem médica do termo. É isso que lhe permite inferir como há de ser a sua intenção, uma Oração apositiva, que é então marcada como fruto de um cálculo mental. Por ocupar a adjacência dessa Oração apositiva, o evidencial parentético tem escopo sobre toda ela. 
(23) Até porque, quem quer beber, bebe do mesmo jeito, só que do lado de fora, causando confusões tremendas, como invasão de jardins com churrasqueiras improvisadas, urina no meio da rua, nos muros e nos gramados alheios; lixo por todo lado, moradores ameaçados e invadidos nos seus direitos. Tanto é verdade que, antes de os jogos começarem, os estádios encontram-se relativamente vazios e, cinco minutos antes do início da partida, e cinco minutos antes do início da partida, se enchem de repente. Mas onde estava esse povo?, me pergunto. Lá fora, bebendo, deduzo. (JSI:otempo).

Nessa ocorrência, a partir do que sabe sobre a proibição de venda de bebidas alcoólicas dentro do estádio, o falante infere que o motivo de as pessoas esperarem até quase a hora do jogo para procurar seus lugares é que estão fora do estádio bebendo. Nesse exemplo, é interessante notar que o escopo do evidencial recai sobre uma Oração não finita, diferentemente do que acontece em (22), em que o parentético escopa uma Oração finita.

(24) Critica também a velocidade e agilidade no caso jurídico do ex-presidente. Está tudo errado, caracterizando, deduzo, má fé do articulista. (JSI:estadao).

Em (24), o escopo da inferência recai sobre um único constituinte da Oração. Nela, a partir do comportamento do articulista, o falante infere que a situação caracteriza má fé desse outro indivíduo. Nessa ocorrência, apenas o Objeto do verbo caracterizar é marcado como inferido, e a Oração parentética é introduzida entre o predicado e o argumento para marcar esse escopo específico.

Assim como acontece com a modificação, a parentetização apresenta um comportamento diferente da complementação e da justaposição, pois ela pode ter escopo tanto sobre Orações quanto sobre unidades menores do que a Oração. Consequentemente, as Orações evidenciais modificadoras e parentéticas demonstram maior mobilidade morfossintática no enunciado e podem, então, ser inseridas em diferentes posições a depender do escopo do elemento que é inferido.

Os subtipos evidenciais, as relações morfossintáticas e o tipo de estrutura inferida ou deduzida são equacionados no quadro a seguir: 
Quadro 1. Forma do elemento inferido ou deduzido nas relações morfossintáticas estabelecidas pela inferência e pela dedução

\begin{tabular}{|c|c|c|}
\hline \multirow{2}{*}{ Relação morfossintática } & \multicolumn{2}{|c|}{ Subtipo evidencial } \\
\cline { 2 - 3 } & Inferência & Dedução \\
\hline \multirow{2}{*}{ Complementação } & $\begin{array}{c}\text { Oração finita } \\
\text { Oração não finita } \\
\text { Sintagma não oracional }\end{array}$ & $\begin{array}{c}\text { Oração finita } \\
\text { Sintagma não oracional }\end{array}$ \\
\hline Justaposição & Oração finita & Oração finita \\
\hline Modificação & $\begin{array}{c}\text { Oração finita } \\
\text { Sintagma não oracional }\end{array}$ \\
\hline Parentetização & $\begin{array}{c}\text { Oração finita } \\
\text { Oração não finita } \\
\text { Sintagma não oracional }\end{array}$ \\
\hline
\end{tabular}

Fonte: Elaboração própria

\section{Considerações finais}

Os dados observados indicam que a codificação da inferência e da dedução em português acontece de forma diferente. A inferência, nos dados analisados, é expressa em mais relações morfossintáticas do que a dedução, já que a primeira é codificada em relações de complementação, justaposição, modificação e parentetização, e a segunda aparece apenas nas relações de complementação e justaposição.

Mesmo na complementação, que é a relação mais frequente para expressar ambos os subtipos evidenciais, a inferência apresenta mais possibilidades de combinação do que a dedução com relação ao tipo de estrutura de seu complemento. Enquanto a posição de Objeto do verbo inferencial pode ser ocupada por uma Oração finita, por uma Oração não finita e por um Sintagma não oracional, na dedução o complemento pode ser uma Oração finita ou um Sintagma não oracional somente. Além disso, o complemento não oracional da inferência pode ser um nome substantival ou um pronome que faça referência a uma Oração, ao passo que, na dedução, o complemento pode ser apenas desse segundo tipo.

Por último, vale ressaltar que, na inferência, constituintes específicos da Oração podem ser marcados como provenientes de um cálculo mental, já que esse subtipo também é codificado por Orações modificadoras e parentéticas, que têm maior liberdade de posicionamento dentro do enunciado e podem focalizar tanto a Oração como um todo quanto somente um de seus constituintes. 


\section{Agradecimentos}

Agradeço à Coordenação de Aperfeiçoamento de Pessoal de Nível Superior (CAPES) pela bolsa concedida para que esta pesquisa fosse realizada como projeto de mestrado, intitulado "A expressão lexical da dedução e da inferência em língua portuguesa: uma análise discursivo-funcional", sob a orientação da Profa. Dra. Marize M. Dall'Aglio-Hattnher.

\section{REFERÊNCIAS}

AIKHENVALD, A. Y. A Grammar of Tariana, from Northwest Amazonia. Cambridge: Cambridge University Press, 2003.

HAAN, F. Encoding speaker perspective: evidentials. In: FRAJZYNGIER, Z.; HODGES, A.; ROOD, D. (ed.). Linguistic diversity and language theories. Amsterdam: Benjamins, 2005. p. 379-397.

HATTNHER, M. M. D. The interaction between tense and evidentials of event perception and deduction in Brazilian Native languages. In: MACKENZIE, J. L.; OLBERTZ, H. (ed.). Casebook in Functional Discourse Grammar. Amsterdam: John Benjamins, 2013. p. 39-66.

HASSLER, G. Epistemic modality and evidentiality and their determination on a deictic basis: the case of Romance languages. In: DIEWALD, G.; SMIRNOVA, E. (ed.). Linguistic Realization of Evidentiality in European Languages. Berlin/Nova York: Walter de Gruyter, 2010. p. 223-248.

HENGEVELD, K.; HATTNHER, M. M. D. Four Types of Evidentiality in the Native Languages of Brazil. Linguistics, v. 53, n. 3, p. 479-524, 2015.

HENGEVELD, K.; FISCHER, R. Episodes, New Topics and Conditionals in A'ingae. 2018. Disponível em: http://www.keeshengeveld.nl. Acesso em: 15 jan. 2019.

HENGEVELD, K.; FISCHER, R.; GRANDIS, S. A'ingae (Cofán/Kofán) Operators. Open Linguistics, v. 4, p. 328-355, 2018.

HENGEVELD, K.; MACKENZIE, L. Functional Discourse Grammar. A typologically-based theory of language structure. Oxford: Oxford University Press, 2008. 
KAPP-BARBOSA, A. M. Usos do verbo saber e a expressão da evidencialidade no português brasileiro. 2017. Tese (Doutorado em Estudos Linguísticos) - Instituto de Biociências, Letras e Ciências Exatas, Universidade Estadual Paulista "Júlio de Mesquita Filho", São José do Rio Preto, 2017.

SARDINHA, T. B.; MOREIRA FILHO, J. L.; ALAMBERT, E. Corpus Brasileiro. São Paulo: CEPRIL, LAEL, CNPq, Fapesp, PUCSP. 2010.

SILVA, V. H. S. A expressão lexical da dedução e da inferência em língua portuguesa: uma análise discursivo-funcional. 2020. Dissertação (Mestrado em Estudos Linguísticos) Instituto de Biociências, Letras e Ciências Exatas, Universidade Estadual Paulista "Júlio de Mesquita Filho", São José do Rio Preto, 2020.

TRAMPUS, M.; NOVAK, B. The Internals Of An Aggregated Web News Feed. Proceedings of 15th Multiconference on Information Society. 2012.

VENDRAME, V. Os verbos ver, ouvir e sentir e a expressão da evidencialidade em língua portuguesa. 2010. Tese (Doutorado em Estudos Linguísticos) - Instituto de Biociências, Letras e Ciências Exatas, Universidade Estadual Paulista "Júlio de Mesquita Filho", São José do Rio Preto, 2010.

VENDRAME-FERRARI, V. Orações complexas com verbos de percepção como forma de expressão da evidencialidade. Estudos Linguísticos, v. 41, n. 1, p. 101-115, jan./abr. 2012. 